\title{
NOTES ON GONTRIBUTORS
}

Brockbank, William, T.D., M.A., M.D. Camb., e.R.c.P., Physician to the Manchester Royal Infirmary. Author of Portrait of a Hospital (1952), and Ancient Therapeutic Arts (1954), etc.

Dukes, Guthbert, O.B.e., M.D., F.r.c.s., President, Section of the History of Medicine, Royal Society of Medicine.

Finch, Sir ERnest, M.D., M.s., D.sc., F.R.c.s., Consultant Surgeon, Royal Infirmary, Sheffield; Hon. Lecturer, History of Medicine, University of Sheffield (late Professor of Surgery).

Holnoway, S. W. F., B.A., late Research Student, Department of History, University College, London.

Lewis, J. Tudor, M.D., D.P.H., Medical Officer of Health, Metropolitan Boroughs of Battersea and Wandsworth.

Lyald, Alexander, M.D., F.R.c.P., Physician for Metabolic Diseases, Aberdeen General Hospitals; Lecturer in Clinical Chemistry, University of Aberdeen; Clinical Chemist, Aberdeen Royal Infirmary, etc.

Ritchie, John, M.B., F.R.c.P. Edin. (1882-I959), Medical Officer for Health of Dumfriesshire; member of the General Medical Council; President of the Scottish Society of the History of Medicine (195I-4).

Singer, Gharles, m.d., D.litt., D.sc., F.r.c.p., Emeritus Professor of the History of Medicine, University of London; Honorary Fellow of Magdalen College, Oxford, and University College, London.

Sorsby, Arnold, M.D., F.R.c.s., Research Professor in Ophthalmology, Royal College of Surgeons and Royal Eye Hospital. Author of Short History of Ophthalmology, and ed. (1948), etc.

Wilson, Thomas Grorge, M.в., litt.d., F.r.c.s., President of the Royal College of Surgeons in Ireland. Author of Victorian Doctor: Life of Sir William Wilde (1942), etc. 